\title{
Validation of three back-calculation models by using multiple oxytetracycline marks formed in the otoliths and scales of bluegill $\times$ green sunfish hybrids
}

\author{
Robert A. Klumb, Michael A. Bozek, and Richard V. Frie
}

\begin{abstract}
We assessed the accuracy of the Fraser-Lee, biological-intercept, and Weisberg back-calculation models to estimate growth from otoliths and scales of laboratory-reared juvenile bluegill $\times$ green sunfish hybrids (Lepomis macrochirus $\times$ Lepomis cyanellus). Hybrid sunfish were injected three times with oxytetracycline hydrochloride at 90 day intervals to mark bony structures, creating simulated annuli for model validation. Back-calculated lengths (BCLs) with otoliths were generally less accurate than scales for all three models. Errors ranged from -8.2 to $7.8 \%$ for the Fraser-Lee model, from -8.0 to $8.3 \%$ for the biological-intercept model, and from -6.5 to $14.3 \%$ for the Weisberg model. For all three models, there was no significant difference in BCLs using left or right otoliths, and BCLs using the Fraser-Lee and biological-intercept models were not significantly different from each other. In contrast with otoliths, all three models produced accurate BCLs from scales; errors ranged from -4.3 to $0.1 \%$. For juvenile hybrid sunfish, we recommend using scales for back-calculation of growth. The Fraser-Lee (with zero intercept) and biologicalintercept models produced the most accurate BCLs from otoliths. However, due to potential decoupling of otolith and body growth, caution should be exercised when estimating juvenile hybrid sunfish growth from otoliths.

Résumé : Nous avons évalué la précision des modèles de rétrocalcul de Fraser-Lee, de l'ordonnée à l'origine biologique et de Weisberg dans l'estimation de la croissance à partir des otolithes et des écailles chez des hybrides du Crapet arlequin et du Crapet vert (Lepomis macrochirus $\times$ Lepomis cyanellus) élevés en laboratoire. Les crapets hybrides ont été injectés à trois reprises avec de l'hydrochlorure d'oxytétracycline à intervalles de 90 jours afin de marquer les structures osseuses et ainsi créer des annulus simulés pour valider les modèles. Les longueurs obtenues par rétrocalcul à partir des otolithes étaient, en règle générale, moins précises que celles obtenues au moyen des écailles, et cela dans tous les modèles. Les erreurs variaient de $-8,2$ à 7,8\% dans le modèle Fraser-Lee, de $-8,0$ à $8,3 \%$ dans le modèle de l'ordonnée à l'origine biologique et de $-6,5$ à 14,3\% dans le modèle de Weisberg. Dans les trois modèles, les longueurs obtenues par rétrocalcul ne différaient pas, qu'on ait utilisé l'otolithe gauche ou le droit; les résultats obtenus par les modèles de FraserLee et de l'ordonnée à l'origine biologique n'étaient pas significativement différents. Contrairement aux résultats obtenus à partir des otolithes, ceux provenant de l'étude des écailles étaient plus précis avec des erreurs allant de $-4,3$ à $0,1 \%$ dans les trois modèles. Nous recommandons donc d'utiliser les écailles pour le rétrocalcul de la croissance chez les jeunes crapets hybrides. Les modèles de Fraser-Lee (avec ordonnée à l'origine de 0) et de l'ordonnée à l'origine biologique ont fourni les meilleures estimations de BCL à partir des otolithes. Cependant, il est possible que la croissance des otolithes ne soit pas couplée à celle du corps; il faut donc faire preuve de prudence lorsqu'on veut estimer la croissance de jeunes crapets juvéniles par l'étude des otolithes.
\end{abstract}

[Traduit par la Rédaction]

\section{Introduction}

Back-calculation models are valuable because they provide growth data for fish populations from a single sampling event and have been used for over 80 years in fisheries management and research. In the field, fish length is measured and calcified structures (scales, otoliths, etc.) are collected for growth analyses. Subsequent age assessment and radial

Received March 17, 2000. Accepted November 16, 2000. Published on the NRC Research Press Web site on January 29, 2001. $\mathrm{J} 15669$

R.A. Klumb $b^{1,2}$ and M.A. Bozek. Wisconsin Cooperative Fishery Research Unit, ${ }^{3}$ University of Wisconsin, Stevens Point, WI 54481, U.S.A.

R.V. Frie. ${ }^{4}$ Wisconsin Cooperative Fishery Research Unit, ${ }^{3}$ University of Wisconsin, Stevens Point, WI 54481, U.S.A., and College of Natural Resources, University of Wisconsin, Stevens Point, WI 54481, U.S.A.

${ }^{1}$ Corresponding author (e-mail: rak11@cornell.edu).

${ }^{2}$ Present address: Cornell University Biological Field Station, 900 Shackelton Point Road, Bridgeport, NY 13030-9791, U.S.A. ${ }^{3}$ Cooperators are the Biological Resources Division of the United States Geological Survey, the Wisconsin Department of Natural Resources, and the University of Wisconsin-Stevens Point.

${ }^{4}$ Deceased. 
measurements to the annuli, along with the length of the fish at capture, are input into a back-calculation model that reconstructs the entire growth history of the individual fish for studies of population dynamics.

The economy and relative ease of obtaining growth histories with back-calculation have resulted in widespread use of this technique (DeVries and Frie 1996), yet few studies in the laboratory (Everhart 1948; Bradford and Geen 1987; Klumb et al. 1999a) have assessed model performance. Validation of back-calculation models provides fisheries managers and researchers confidence that observed growth differences within or among fish populations are real and not artifacts of invalid model assumptions or techniques. Francis (1990) listed three components needed to truly validate a back-calculation method: ( $i$ ) the radius of yearly marks must remain constant from the time of formation (i.e., scale or otolith radii to respective annuli do not change once formed), (ii) the mark is a true annulus, formed on a yearly basis, and (iii) the formula used to back-calculate growth accurately describes the body-scale or body-otolith relationship. Requirements for conducting true validation are met only in field mark-recapture studies (Davies and Sloane 1986; Howells et al. 1995; Klumb et al. 1999b) or laboratory studies (Bradford and Geen 1987; Klumb et al. 1999a) where length measurements at the time of marking (the standard for comparison) are compared with back-calculated lengths (BCLs) from the same fish.

Casselman (1983) stated that the best evidence for validation requires data from fish marked with a fluorescent chemical or physical tag and then later recaptured, producing known increments of growth for comparison. Tetracycline antibiotics are incorporated into actively calcifying new bone, forming a yellow-gold mark visible under ultraviolet light (Weber and Ridgway 1962). Rapid deposition of tetracycline is required for accurate and precise marks, used as reference points in time, to form in the bones and scales of fish. Babaluk and Craig (1990) found that $100 \%$ of northern pike (Esox lucius) scales and otoliths were marked within $12 \mathrm{~h}$. Within $24 \mathrm{~h}$ of injection, $100 \%$ of starry flounder (Platichthys stellatus) otoliths were successfully marked (Campana and Neilson 1982).

Bluegill (Lepomis macrochirus) and bluegill $\times$ green sunfish hybrid (Lepomis macrochirus $\times$ Lepomis cyanellus) scales have been successfully marked with oxytetracycline (OTC) by feeding, and these OTC marks were used for back-calculation model validation (Klumb et al. 1999a). No literature exists assessing the success of marking Lepomis sp. otoliths or scales by OTC injection. We present here the results of a laboratory experiment used to validate backcalculation growth models with OTC injection. The objectives of this study were to $(i)$ assess marking success in otoliths and scales of bluegill $\times$ green sunfish hybrids raised in the laboratory and marked multiple times by injection with OTC, (ii) assess and validate the Fraser-Lee, biologicalintercept (Campana 1990), and Weisberg (Weisberg 1986) back-calculation models, (iii) compare BCLs derived from three otolith radii with scales, (iv) compare otolith backcalculations using left and right otoliths from the same fish, and $(v)$ determine the effect of known scale measurement error on BCLs.

\section{Methods}

Age-1 bluegill $\times$ green sunfish hybrids, hereafter referred to as hybrid sunfish, were injected three times with OTC at 90-day intervals (Kobayashi et al. 1964) to "simulate" annuli for backcalculation model validation; fish were generally of uniform total length (Table 1). Since fish were not individually tagged for identification (i.e., numbered tags), mean observed growth of all OTCinjected fish for each 90-day interval was compared with their mean BCL. The number and percentage of hybrid sunfish with multiple OTC marks in their otoliths and scales were assessed only for fish surviving the entire experiment.

Fish $(N=97)$ were injected intraperitoneally near the anus (Babaluk and Craig 1990) at a dosage of $75 \mathrm{mg} \mathrm{OTC} \cdot \mathrm{kg} \mathrm{fish}{ }^{-1}$ with Anchor OXY-TET 50 (oxytetracycline hydrochloride; Boehringer Ingelhein Animal Health Inc., St. Joseph, Mo.) sold at $50 \mathrm{mg}$ OTC $\cdot \mathrm{mL}^{-1}$. If OTC appeared to seep from the injection wound, the fish was given a second injection. Immediate postinjection mortality was low; only one fish died within 1 day after injection. Control fish $(N=20)$, not injected with OTC, were raised in the same tank with the OTC-treated fish to ensure that no natural fluorescent marks in otoliths and scales occurred. The right pelvic fin and top lobe of the caudal fin were clipped to identify control fish.

To simulate "interannual" environmental variation, we attempted to vary growth rates between marking intervals by changing water temperature. Target temperatures for the three successive growth periods were 20,15 , and $25^{\circ} \mathrm{C}$, respectively. Mean temperatures for each interval were within $\pm 2{ }^{\circ} \mathrm{C}$ of the targeted temperature (Table 1).

Two complete 90-day growth periods were completed with all fish, while a reduced number were used for the third growth period. A cracked submersible heater electrocuted 73 fish (55 experimental fish and 18 control fish); 38 experimental and two control fish survived and were used to complete the experiment. For the two groups of fish, BCLs were compared with the observed lengths at the first two OTC marks for the electrocuted fish and at all three OTC marks for fish surviving the entire experiment. Instantaneous growth rates for each 90-day interval were calculated using the formula in Ricker (1979).

Fish were raised in flow-through fiberglass raceways. Tanks received tap water at an average of $2 \mathrm{~L} \cdot \mathrm{min}^{-1}$, providing about six water exchanges per day; current was negligible. Photoperiod was kept constant (17 h light : $7 \mathrm{~h}$ dark) and dissolved oxygen was monitored to ensure that levels remained above $5 \mathrm{mg} \cdot \mathrm{L}^{-1}$. Mean dissolved oxygen remained above $8 \mathrm{mg} \cdot \mathrm{L}^{-1}$ throughout the experiment. Fish were fed daily at $2 \%$ of body weight with trout fry No. 4 granules ( $47 \%$ protein), $4.8-\mathrm{mm}$ pellets (41\% protein), or $3.2-\mathrm{mm}$ pellets (40\% protein) administered by $12-$ or $24-\mathrm{h}$ automatic belt feeders. Ration was adjusted every 90 days after each OTC treatment or when excessive mortality occurred (i.e., total ration reduced proportional to mortality).

\section{Sample collection and preparation}

At the time of each OTC injection, all treatment and control fish were anesthetized with tricaine methanesulfonate (MS 222), total length was measured to the nearest millimetre (with depressed caudal fin), and weight was measured to the nearest $0.1 \mathrm{~g}$. At the end of the experiment, otoliths (both sagittae) and scales (approximately 10-20) were collected. Left and right sagittae were analyzed separately. Otoliths for all species were wiped clean after removal and soaked in glycerin for 2 weeks to help them clear (Maceina and Betsill 1987). Scales were removed from the left side, below the lateral line, and anterior to the distal point of the pectoral fin when pressed against the body (Regier 1962).

Back-calculations were derived from three otolith radii: the anterior, dorsal, and posterior axes (Fig. 1). Otoliths were viewed 
Table 1. Mean total length of hybrid sunfish at the time of OTC marking, instantaneous growth rates, and water temperatures in the laboratory during the three 90-day experimental treatments used to validate back-calculation growth models.

\begin{tabular}{lrllll}
\hline $\begin{array}{l}\text { OTC } \\
\text { mark }\end{array}$ & \multicolumn{1}{c}{$N$} & $\begin{array}{l}\text { Mean length } \\
\pm 2 \mathrm{SE}(\mathrm{mm})\end{array}$ & $\begin{array}{l}\text { Instantaneous growth } \\
\text { rate }\left(\mathrm{mm} \cdot \mathrm{day}^{-1}\right)\end{array}$ & $\begin{array}{l}\text { Mean water temperature } \\
\pm 2 \mathrm{SE}\left({ }^{\circ} \mathrm{C}\right)\end{array}$ & $\begin{array}{l}\text { Temperature } \\
\text { range }\left({ }^{\circ} \mathrm{C}\right)\end{array}$ \\
\hline 1 & 97 & $119.9 \pm 2.6$ & 0.002694 & $20 \pm 0.2$ & $23-18$ \\
$2 *$ & 101 & $152.8 \pm 3.4$ & 0.001437 & $17 \pm 0.4$ & $20-14$ \\
$3 \dagger$ & 37 & $173.9 \pm 4.8$ & 0.000481 & $23 \pm 0.4$ & $26-18$ \\
\hline
\end{tabular}

Note: Mean length $\pm 2 \mathrm{SE}$ at the end of the experiment was $181.6 \pm 5.6 \mathrm{~mm}$.

*Four control fish were not identified and were included in the treatment group.

$\dagger$ Fifty-five experimental fish were electrocuted between OTC treatments 2 and 3 .

whole with the sulcus side down. Sample sizes for the three axes differed slightly because no measurements were made along any axis that was chipped or broken or for fish without the expected number of OTC marks visible along a particular axis (Table 2). Measurements were made to the edge of the OTC mark proximal to the otolith core, and this point in time was assumed to correspond to body length measurements made before treatment (Campana and Neilson 1982).

The mean scale radius for each fish $(N=3)$ was used for backcalculation (Newman and Weisberg 1987). Scales were measured from the focus to the anteriolateral corner (anteriolateral axis) (Fig. 1). The edge of the OTC mark proximal to the scale focus was used as the point for validation of the back-calculation models and was assumed to have formed immediately after OTC treatment (Campana and Neilson 1982). For all fish, scale radii were measured from the scale focus to that point. No regenerated scales were used, and only scales from fish with the expected number of OTC marks were measured.

Because OTC marks typically create fluorescent bands that are two to three circuli wide in the scales of injected fish (Kobayashi et al. 1964; Bumguardner 1991), mark width was used to assess the effect of scale measurement error on BCLs. The widths of the OTC marks for 30 randomly selected fish were measured and the circuli in the OTC band were counted. Measurements were made with an occular micrometer at $10 \times$ magnification. To create a known measurement error, scale radii along the same anteriolateral axis were measured to the proximal and distal edges of the OTC mark for all fish. Known scale measurement error was calculated as the percentage of the total scale radius within the OTC fluorescent mark. Differences between BCLs from scale radii measured to the OTC mark inner and outer edges were used for model sensitivity analyses. Consistency of OTC mark width among treatments was tested with a one-way analysis of variance (ANOVA) and Bonferroni multiple-range test.

\section{Detection of OTC marks and measurement techniques}

The OTC marks in otoliths and scales were detected with an Olympus Vanox model AHBT compound microscope fitted with an AH2-RFL attachment for reflected and transmitted fluorescence. The excitation wavelength that provided the best fluorescence was the violet range (395-415 nm); Bumguardner (1991) used similar wavelengths. The factory-installed DM 455 dichroic mirror $(455 \mathrm{~nm})$, BP405 exciter filter $(405 \mathrm{~nm})$, and Y455 barrier filter $(455 \mathrm{~nm})$ were used without any supplementary barrier or exciter filters. The lamp source was a $200-\mathrm{W}$ high-pressure mercury burner. Objective magnification was $2.5 \times$.

High OTC mark intensity enabled otolith and scale radii to be measured with a digital image analysis system. Video images were created using an MTI series $68 \mathrm{mk}$ II camera (Dage-MTI, Inc., Michigan City, Ind.) mounted on the microscope, and digital images were captured with a Targa+ framegrabber (Truevision, Inc., Indianapolis, Ind.). Images were processed and measured using the software Mocha ${ }^{\mathrm{TM}}$ v.1.2.10 (Jandel Scientific, San Rafael, Calif.). To view real-time images on a video monitor, an Olympus NFK
$1.67 \times$ projection lens for the video camera was used for otolith images and an Olympus NFK $2.5 \times$ lens for scale images. Separate calibrations for otolith and scale images were done with a hemacytometer. Measurement error of the digital analysis system was $0.34 \%$ for otoliths and $0.48 \%$ for scales.

The OTC marks and the otolith core or scale focus required different techniques to maximize their contrast and resolution. Otoliths were immersed in glycerin during observation to improve contrast. A combination of brightfield and fluorescent microscopy was used to enhance contrast of the otolith core and scale focus. To properly locate the core or focus, a second image using brightfield illumination was made without moving the sample after collecting the image under fluorescent illumination. Annotation features in the software were then used to create an overlay on the brightfield image to locate the otolith core and scale focus, which was then overlain on the image with the visible OTC marks. A daylight/ tungsten (blue filter), green filter, and neutral density filter were used during brightfield observation. Hybrid sunfish scales were soaked in glycerin for 2 days to clear and improve the contrast of the OTC mark (Bumguardner 1991). Quality of the OTC marks differed based on the side of the scale viewed under the microscope (i.e., fibrillary plate versus grooved) and were clearer when viewed with the grooved side up. High intensity of the OTC marks enabled scales to be viewed dry, mounted between a glass slide and coverslip.

\section{Back-calculation models and analyses}

The Fraser-Lee (i.e., intercept-corrected direct proportion) model is a linear, direct proportional back-calculation method (Fraser 1916; Lee 1920) that back-calculates length for individual fish as

$$
L_{i}=a+\left(L_{\mathrm{c}}-a\right)\left(S_{i} / S_{\mathrm{c}}\right)
$$

where $L_{i}$ is BCL at annulus $i, L_{\mathrm{c}}$ is length at capture, $S_{i}$ is scale (bony structure) radius to annulus $i, S_{\mathrm{c}}$ is total scale (bony structure) radius, and $a$ is a correction factor.

The correction factor $a$ proposed by Fraser (1916) represents the length of the fish at the time of scale formation. The correction factor is commonly derived empirically from observations of larval and juvenile fish (Everhart 1948) or mathematically from the $y$-intercept of a linear regression of body length on scale radius (Lee 1920; Whitney and Carlander 1956; Carlander 1982) and hereafter is referred to as an "intercept." No intercept was used for otolith back-calculations because otoliths are present at hatching or soon thereafter (Taubert and Coble 1977; Schramm et al. 1992). A zerointercept reduces the Fraser-Lee model to the direct proportional or Dahl-Lea model (Dahl 1907; Lea 1910) for mean BCLs. For Fraser-Lee back-calculations from scales, we used the 20-mm bluegill standard intercept value recommended by Carlander (1982). A 20-mm intercept provided accurate BCLs and was recommended as a standard for hybrid sunfish (Klumb et al. 1999a).

Campana (1990) proposed a modification to the Fraser-Lee model, known as the biological-intercept model, to account for systematic variation in the fish length - otolith size ratio with somatic 
Fig. 1. (A) Anterior, dorsal, and posterior axes measured on whole otoliths and (B) anteriolateral axis measured on scales for back-calculation.

(A)

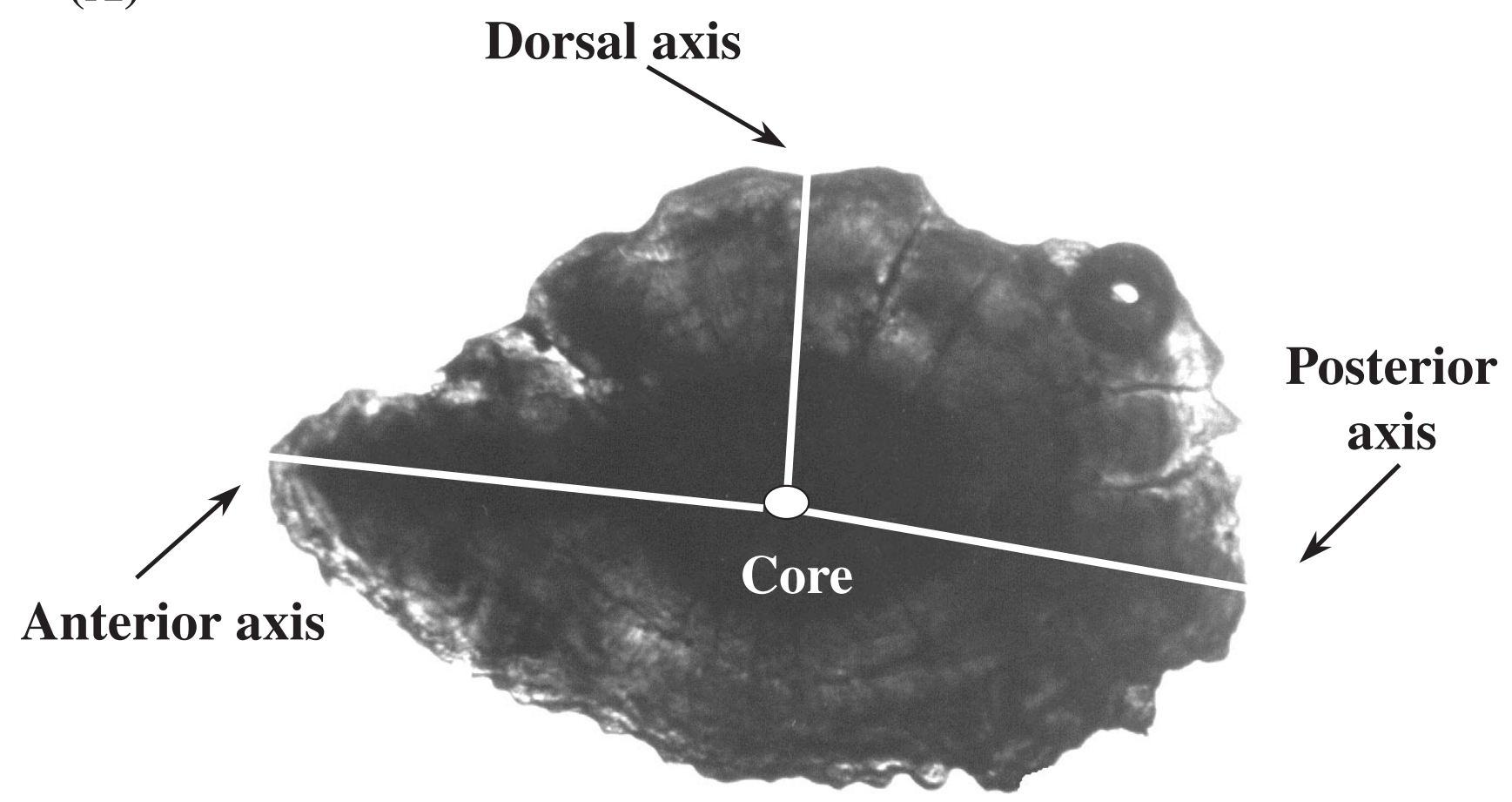

(B)

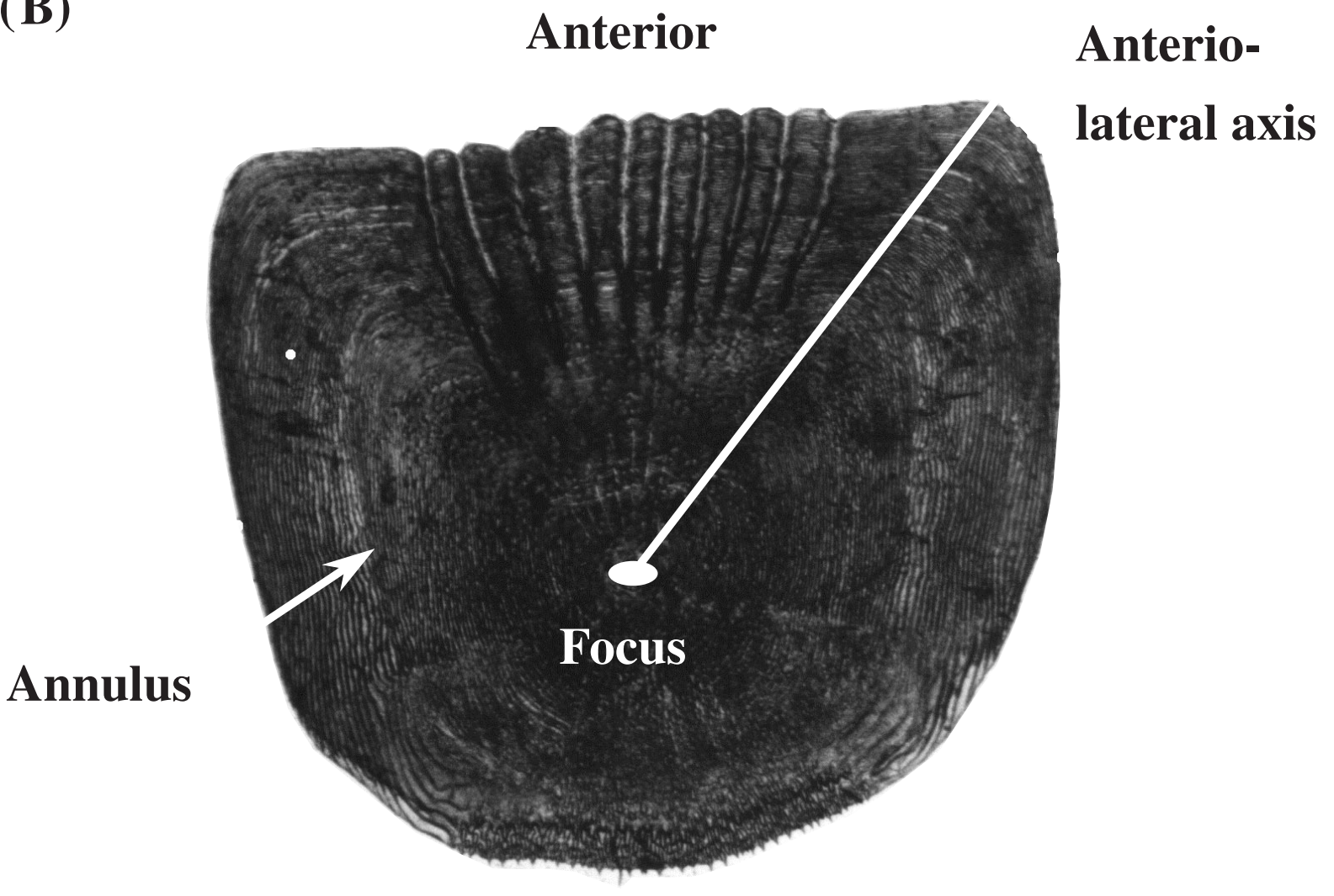

\section{Posterior}


Table 2. Numbers of OTC-marked hybrid sunfish with scales and otoliths used for back-calculation.

\begin{tabular}{lllll}
\hline \multirow{2}{*}{$\begin{array}{l}\text { OTC } \\
\text { mark }\end{array}$} & Scales & Otoliths & \\
\cline { 3 - 5 } & Anterior axis & Dorsal axis & Posterior axis \\
\hline 1 & 83 & $40 \mathrm{~L}, 47 \mathrm{R}$ & $67 \mathrm{~L}, 61 \mathrm{R}$ & $63 \mathrm{~L}, 52 \mathrm{R}$ \\
2 & 83 & $40 \mathrm{~L}, 47 \mathrm{R}$ & $67 \mathrm{~L}, 61 \mathrm{R}$ & $63 \mathrm{~L}, 52 \mathrm{R}$ \\
3 & 28 & $13 \mathrm{~L}, 14 \mathrm{R}$ & $22 \mathrm{~L}, 16 \mathrm{R}$ & $17 \mathrm{~L}, 15 \mathrm{R}$ \\
\hline
\end{tabular}

Note: Left $(\mathrm{L})$ and right $(\mathrm{R})$ otoliths were analyzed separately along three axes.

growth rate. Essentially, the Fraser-Lee model is corrected along both the $x$ - and $y$-axes using biologically determined intercepts corresponding to the onset of proportional growth between the body and bony structure. Campana's (1990) biological-intercept model back-calculates length for individual fish as

$$
L_{i}=L_{\mathrm{c}}+\left(L_{\mathrm{c}}-L_{0}\right)\left(S_{i}-S_{\mathrm{c}}\right) /\left(S_{\mathrm{c}}-S_{0}\right)
$$

where $L_{i}$ is BCL at annulus $i, L_{\mathrm{c}}$ is length at capture, $S_{i}$ is scale (bony structure) radius to annulus $i, S_{\mathrm{c}}$ is total scale (bony structure) radius, $L_{0}$ is a correction factor for body length, and $S_{0}$ is a correction factor for bony structure length. For otoliths, we used the corrections of Hales and Belk (1992) corresponding to a total length of $6 \mathrm{~mm}\left(L_{0}\right)$ for bluegill larvae at swim-up and an otolith radius at swim-up of $0.04 \mathrm{~mm}\left(S_{0}\right)$ found by Taubert and Coble (1977) for the posterior axis. We used this correction factor for all three axes. For scale back-calculations, proportionality is generally assumed to start at scale formation. Bluegills attain a body length of approximately $20 \mathrm{~mm}$ at scale formation (Potter 1925), and we set $S_{0}=0$; this results in Campana's model being identical to the original Fraser-Lee model.

The Weisberg linear model partitions fish growth into two main effects: growth due to age of the fish and growth due to environmental effects in a given year (Weisberg and Frie 1987; Weisberg 1993) in a general additive ANOVA model:

$$
\mu_{a j}=(\text { age effect })_{a+1-j}+(\text { year effect })_{j}
$$

where $\mu_{a j}$ is the population mean bony structure increment for fish of age a that grew in year $j, a$ is age, and $j$ is year of growth $(j=1$ is the most current year of growth).

Back-calculation in the Weisberg model is a multistep process. First, an ANOVA model is fit to bony structure increments to estimate the effects (i.e., coefficients) of age and the environment on mean bony structure increments. A regression of total length on bony structure radius is then calculated and the parameters are derived by maximum likelihood estimation. Length increments are then modeled for age effects and year effects with the coefficients derived by maximum likelihood estimation. Lastly, the estimated mean length increments for each age in a given year are summed to give the total $\mathrm{BCL}$.

Assumptions for the Weisberg model are that (i) bony structure and length increments have a joint normal distribution, (ii) growth increments for a fish are independent among years, (iii) fish in the same year grow independently of each other, and (iv) the errors are normally distributed. For the body - bony structure regression, the model assumes that the correlation $(\rho)$ between body and bony structure growth is constant for all years and all age groups in the sample. Therefore, the regression model is fit with a common slope for each age group. An $F$ test checks the assumption that $\rho$ is constant. Each age group can have a unique intercept value. Further details of model calculations are given in Weisberg (1986, 1993) and Weisberg and Frie (1987). Back-calculations were obtained with the XLISP-STAT computer program in a Windows ${ }^{\mathrm{TM}}$ environment, version 2.1R3 Alpha 6, Windows ${ }^{\mathrm{TM}}$ version 3.0, provided by the Minnesota Sea Grant Program (S. Weisberg, Department of
Applied Statistics, University of Minnesota, St. Paul, MN 551086042, U.S.A., unpublished manual).

The Weisberg model requires at least two year-classes with a minimum of three fish in each year-class in order to run. Because between the second and third OTC treatments, a defective heater electrocuted approximately $63 \%$ of the fish, the electrocuted fish and surviving fish were treated as two artificial year-classes. Since both groups of fish were actually reared together (up to the time of the accident), no significant year effects were expected.

For all three models, lengths measured at the time of OTC marking were compared with their respective BCLs. Model error was quantified as the percent difference of BCLs from known lengths. To prevent cancellation of positive and negative errors, absolute values were used to calculate the overall mean percent difference. The slope of the line for an individual fish in the FraserLee model has its natural variability constricted due to forcing the line through a common $y$-intercept and results in the variance structure being unknown (Weisberg and Frie 1987; DeVries and Frie 1996). Therefore, Fraser-Lee BCLs were tested against known lengths with the Mann-Whitney $U$ test. Statistical analyses could not be performed for the Weisberg model because it does not backcalculate for individual fish. To assess whether otolith and scale increments remained constant after formation (i.e., Francis' (1990) first validation requirement), we compared otolith and scale radii for the electrocuted and surviving fish at the first two OTC marks. All statistical analyses were performed with SPSS for Windows ${ }^{\mathrm{TM}}$ release 6.1.2. Statistical significance was set at $\alpha=0.05$.

\section{Results}

\section{OTC marking success}

Multiple OTC marking success of hybrid sunfish otoliths was lower than for scales. However, marking success in otoliths and scales was $100 \%$ for the first two marks for the 38 hybrid sunfish that survived all three treatments. Three OTC marks were visible in either the left or right otolith and along at least one axis for $61 \%$ of the 38 fish that survived the experiment (Fig. 2). For scales, three OTC marks were observed in $74 \%$ of the fish surviving all OTC treatments (Fig. 3). Hybrid sunfish growth rates declined with each successive treatment (Table 1); growth declined $47 \%$ from the first to second increments and $66 \%$ from the second to third increments. Sample size for otolith back-calculations differed for the otolith analyzed (right or left) and axis measured due to nonvisible OTC marks along a particular axis and chipped or cracked otoliths (Table 2). A total of $86 \%$ (83) of fish possessed the expected number of OTC marks and had nonregenerated scales usable for back-calculation (Table 2).

\section{Back-calculation model validation}

\section{Otoliths}

Otolith radii measured to the first two OTC marks were not significantly different between fish electrocuted after the second marking period and fish surviving all three OTC treatments for left and right otoliths along all three axes (Table 2). These results indicate that we met Francis' (1990) first requirement for back-calculation model validation; once formed, otolith radii from the core to the first two OTC marks remained constant. Furthermore, the potential error in back-calculating lengths using whole otoliths due to refractive distortion was minimal; differences between otolith radii 
for electrocuted and surviving fish at both OTC marks were $<4 \%$.

The accuracy of Fraser-Lee BCLs based on whole otoliths differed for both the measurement axis used and the OTC mark being analyzed; errors ranged from -8.2 to $7.8 \%$. Overall, no axis consistently provided the most accurate BCLs (Fig. 4). Using the anterior axis, BCLs were significantly different from the actual lengths at the third OTC mark on both right and left otoliths and at the second mark on only the right otolith. BCLs for both the dorsal and posterior axes were significantly different from the actual lengths at the first and third OTC marks on right and left otoliths. There were no significant differences between BCLs using left or right otoliths along all three axes (Mann-Whitney $U$ test: $P>0.05)$. The largest difference between BCLs from left and right otoliths was $4.1 \mathrm{~mm}$ for anterior radii measured to the third OTC mark.

The accuracy of BCLs from the biological-intercept model using whole otoliths also differed for both the measurement axis and the OTC mark being analyzed. Errors ranged from -8.0 to $8.2 \%$, and again, no axis consistently provided the most accurate BCLs (Fig. 4). Significant differences between BCLs and the actual lengths at marking occurred for the same axes and OTC marks as the Fraser-Lee model (Fig. 4): the second and third OTC marks using the anterior axis and the first and third marks using the dorsal and posterior axes. There were no significant differences between BCLs using left or right otoliths along all three axes (Mann-Whitney $U$ test: $P>0.05$ ). Comparing BCLs from the Fraser-Lee and biological-intercept models resulted in no significant differences (Mann-Whitney $U$ test: $P>0.05$ ).

The accuracy of Weisberg BCLs from otoliths differed between measurement axes and OTC marks; errors ranged from -6.5 to $14.3 \%$. No otolith axis consistently provided the most accurate BCLs (Fig. 4). Differences between BCLs derived from left or right otoliths were small; the largest difference was $6 \mathrm{~mm}$ for posterior radii measured to the third OTC mark.

Weisberg model assumptions were not met for all otolith axes, and the otolith increment ANOVA model detected one nonexistent year effect. The constant correlation assumption between otolith and body increments was met for the anterior axis and dorsal axis for right and left otoliths. Along the posterior axis of right and left otoliths, the constant correlation assumption was violated ( $F$ test: right $F=5.3427$, df $=$ $1,48, P=0.02$; left $\mathrm{F}=7.8419$, df $=1,59, P=0.01$ ). Age effects for the otolith increment ANOVAs were significant for all axes and otoliths. The only unexpected significant year effect from the ANOVAs was for left otoliths measured along the anterior axis.

The relative magnitude of over- and underestimation at all three OTC marks was remarkably similar for the Fraser-Lee, biological-intercept, and Weisberg models for all three otolith axes (Fig. 4). For all three models, back-calculations overestimated the known length at the first mark and underestimated length at the second and third marks. Lowest differences for otolith BCLs from actual lengths were always seen at the second OTC mark. Weisberg BCLs from dorsal and posterior measurements overestimated known length by $>10 \%$ for the first OTC mark. No BCLs from otoliths dif- fered from the known length by $>8.5 \%$ for the Fraser-Lee or biological-intercept model.

\section{Scales}

Scale radii measured to the first two OTC marks were not significantly different between fish electrocuted after the second marking period and fish surviving all three OTC treatments (Table 3) and indicate that we met Francis' (1990) first requirement for back-calculation model validation. Differences between scale radii for electrocuted and surviving fish at both OTC marks were $<2 \%$.

For the Fraser-Lee model, the BCLs from scales underestimated the actual length at marking by $0.6-4.3 \%$ (Fig. 4). The overall mean percent difference of BCLs from the actual length at marking was $1.8 \%(2.3 \mathrm{~mm})$. The BCLs were significantly smaller $(4.3 \%, 5.1 \mathrm{~mm})$ than the actual lengths at marking only at the first OTC mark.

Error for Weisberg model BCLs from scales ranged from -2.2 to $0.6 \%$ (Fig. 4). Across all marks, the overall weighted mean difference of Weisberg BCLs was $1.4 \%(1.8 \mathrm{~mm})$ less than the actual lengths at marking. The constant correlation assumption between scale and body increments, requiring equal slopes for the age groups, was met ( $F$ test: $F=0.0459$, df $=1,79, P=0.83)$. For the Weisberg scale increment ANOVA, age effects were significant but year effects, as expected, were not.

Neither the Fraser-Lee nor the Weisberg model consistently provided more accurate estimates of the actual lengths from scale radii of the OTC-injected hybrid sunfish. However, the Fraser-Lee model did consistently underestimate length. The overall BCL mean percent differences from the actual lengths at OTC marking for both models were similar, $1.8 \%$ for the Fraser-Lee model and $1.4 \%$ for the Weisberg model.

\section{OTC mark width and scale measurement error}

Despite using identical concentrations (by percent body weight) of OTC for each injection, the width of marks was not uniform for successive marking attempts in the anteriolateral region of the scale (Table 4). The first mark was significantly wider than the second and third marks (one-way ANOVA: $F=7.888, P=0.001)$. The widest OTC marks were formed before the interval with the highest growth rate (Table 1). The OTC mark widths declined $29.4 \%$ from treatment 1 to treatment 2 .

The mean width of the OTC fluorescence was $0.054 \mathrm{~mm}$; error as a percentage of the total scale radius for marks 1-3 was $1.4 \%$ (Table 4 ). The difference between Fraser-Lee BCLs using radii measured to the inner versus outer OTC mark edges was $1.7,1.5$, and $1.2 \mathrm{~mm}$ for marks $1-3$, respectively. The overall mean difference between BCLs was $1.5 \mathrm{~mm}$. The ratio of the mean change in Fraser-Lee BCLs to the percentage of the scale radius within the OTC mark (i.e., known error) was $1.041 \mathrm{~mm}$ to $1 \%$ error. A scale measurement error of $1 \%$ on Weisberg BCLs resulted in similar differences between the BCLs of 1.7, 1.5, and $1.1 \mathrm{~mm}$ for marks 1-3, respectively. The mean difference between Weisberg BCLs was also $1.5 \mathrm{~mm}$. For the Weisberg model, the ratio of the mean change in BCLs to the percentage of the scale radius in the OTC mark was the same as for the Fraser-Lee model, $1.041 \mathrm{~mm}$ to $1 \%$ error. 
Fig. 2. Whole right otolith from a 191-mm hybrid sunfish showing three OTC marks in the three regions measured for backcalculation: (A) anterior region, (B) dorsal region, and (C) posterior region.
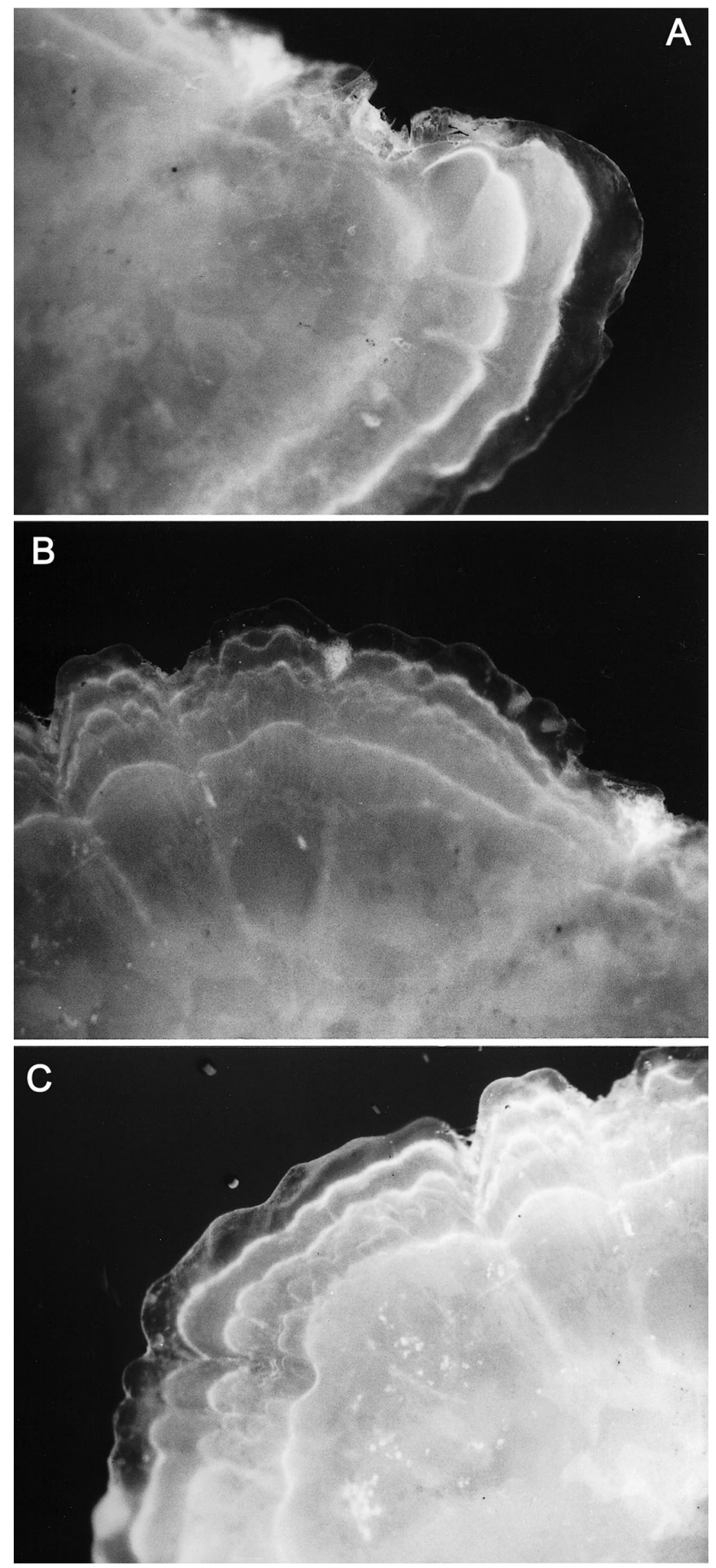
Fig. 3. Comparison of experimental and control bluegill scales indicating the presence and absence of OTC marks. (A) Scale from a 198-mm hybrid sunfish injected with OTC three times and exhibiting three fluorescent marks; (B) scale from a 175-mm control fish not injected with OTC.
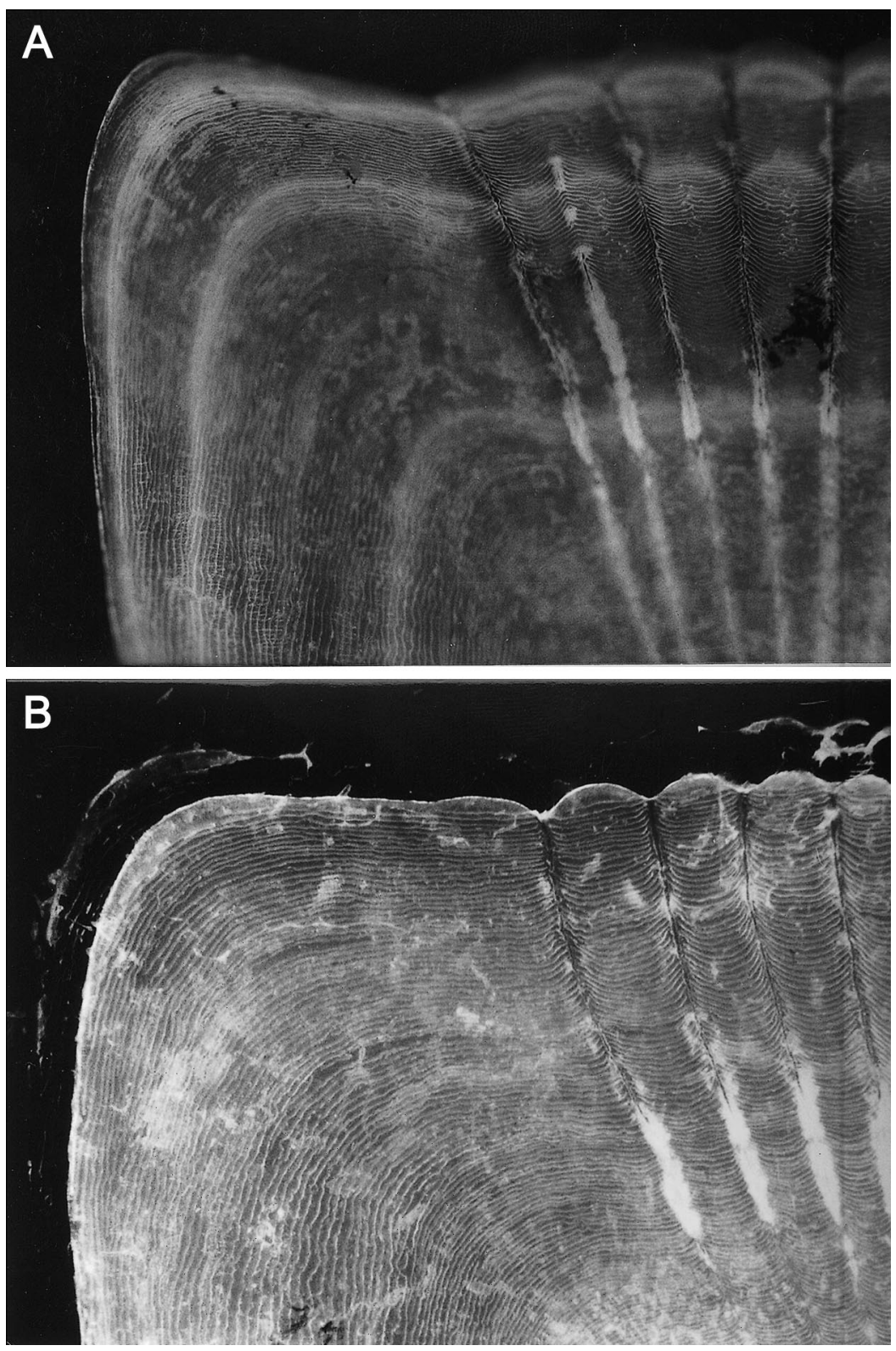

\section{Discussion}

\section{OTC marking success}

Injection is a more direct method of administering OTC than feeding or immersion (Strasdine and McBride 1979), and marking success in otoliths and scales was $100 \%$ for the first two marks for the 38 hybrid sunfish that survived all three treatments. Even though actual growth rates decreased from treatment 1 to treatment 3 , variability of mark intensity was low. Seepage of OTC out of the injection wound and misidentification of four control fish affected marking success. Marking success of OTC-injected fish is generally high and consistent for scales and otoliths from the same fish (Campana and Neilson 1982; Babaluk and Craig 1990). The low marking success that we observed for otoliths may be due to using whole otoliths; use of sectioned otoliths may have increased our overall marking success.

\section{Back-calculated growth}

In this study, OTC marks created in laboratory fish at 90day intervals simulated annuli and removed the possibility of back-calculation error due to incorrect age assessment. These OTC marks met the second requirement for validation of a back-calculation technique (Francis 1990) by removing concern for the validity of natural annuli formation. We found that once formed, the distance between OTC marks remained constant for hybrid sunfish otoliths and scales, Francis' (1990) first validation requirement. Klumb et al. $(1999 b)$ found that scale radii between annuli remained constant for individually marked smallmouth bass (Micropterus 
Fig. 4. Percent differences of BCLs from the observed lengths of hybrid sunfish at the time of OTC marking for the (A) Fraser-Lee, (B) biological-intercept, and (C) Weisberg models. Black bars, scales; open bars, otoliths along the anterior axis; shaded bars, otoliths along the dorsal axis; hatched bars, otoliths along the posterior axis. Asterisks indicate significant differences between observed lengths and BCLs (Mann-Whitney $U$ test: $P<0.05$ ). Only data for right otoliths are provided. Scale BCLs for the Fraser-Lee and biologicalintercept models are identical.
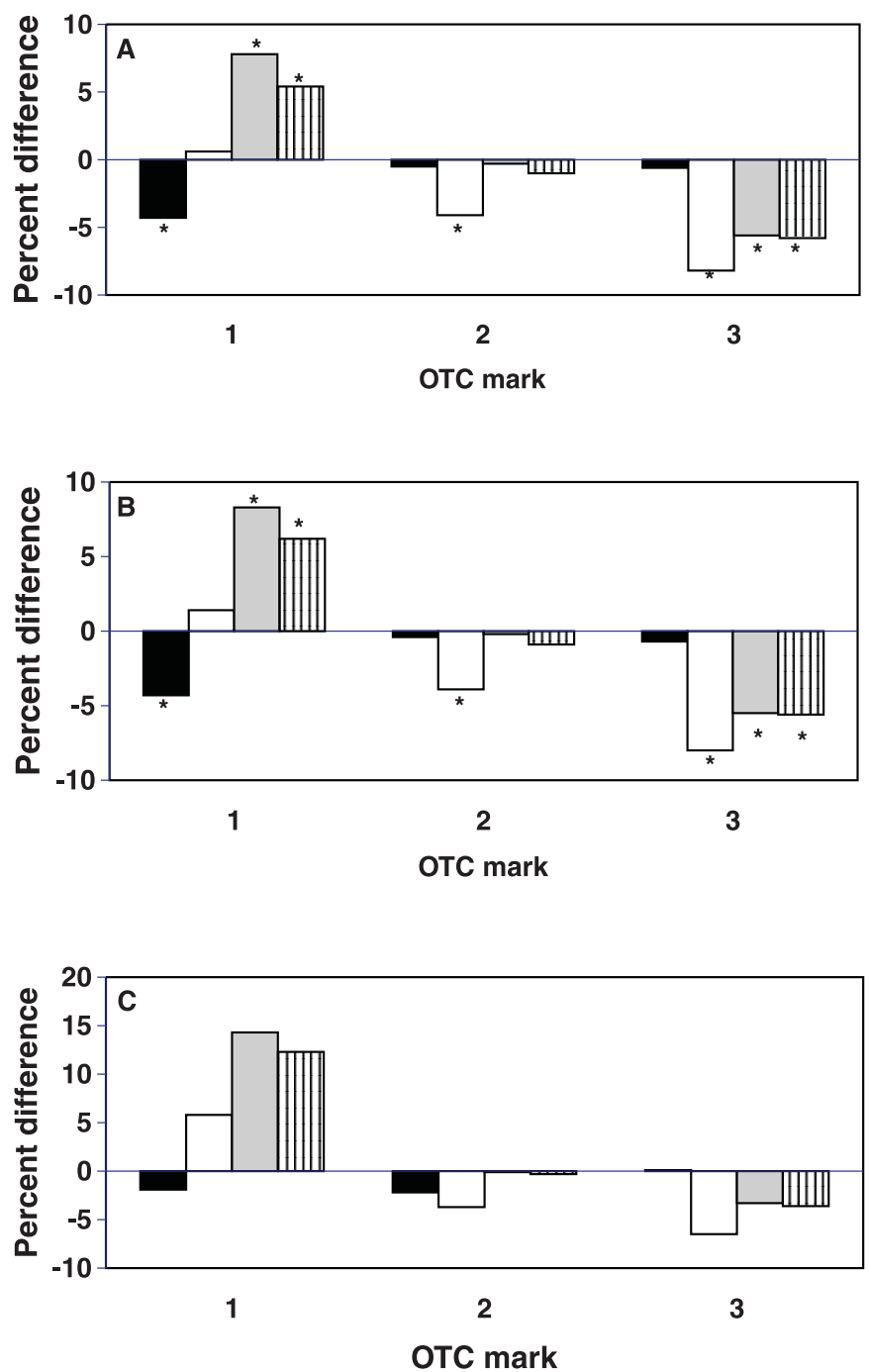

dolomieu) and walleye (Stizostedion vitreum) captured multiple times. As a result, this study focused on how well the back-calculation models estimated past growth.

Otoliths from OTC-injected hybrid sunfish provided less accurate back-calculations than scales for the Fraser-Lee, biological-intercept, and Weisberg models. For all models, none of the three otolith axes consistently provided better length estimates, yet the three models may have detected a similar change in otolith growth along each specific axis with respect to body growth. The otolith to body relationship has been found to vary with season (Rijnsdorp et al. 1990), and Casselman (1990) found that otoliths grew slower than the body during rapid somatic growth. Also, otolith growth has been observed to "decouple" or lag behind changes in somatic growth in juvenile fishes in the laboratory (Wright et al. 1990; Bradford and Geen 1992). The possible decoupling of otolith and somatic growth may explain the greater error in back-calculations for otoliths than for scales in this study. Otolith growth also follows water temperature more closely than ration level (Bradford and Geen 1992). Bradford and Geen (1992) observed decoupling in experiments on juvenile chinook salmon (Oncorhynchus tshawytscha) lasting 70 days with temperatures varied by $5-8.6^{\circ} \mathrm{C}$. In this study, water temperature varied approximately $5^{\circ} \mathrm{C}$ between the 90-day growth intervals, and these changes may have produced decoupling of otolith and somatic growth in our juvenile hybrid sunfish.

The biological-intercept model resulted in otolith BCLs that were not significantly different from BCLs derived from the Fraser-Lee model without an intercept (the Dahl-Lea model) because the small biological-intercept corrections used for larval body and otolith size at swim-up had little effect on estimated growth for the 90-day intervals in this study. However, the biological-intercept modifications have been found to increase accuracy for larval daily growth estimates. Sirois et al. (1998) found that daily growth estimates 
Table 3. Results of $t$ tests (assuming equal variance) comparing hybrid sunfish mean $\pm 2 \mathrm{SE}$ otolith and scale radii ( $\mathrm{mm}$ ) measured to the first and second OTC marks for fish killed (electrocuted) after the second marking attempt and fish surviving all three OTC marking treatments.

\begin{tabular}{ccccc}
\hline OTC mark & Electrocuted fish & Surviving fish & $t$ & $P$ \\
\hline Right otolith, anterior axis & & & \\
1 & $2.40 \pm 0.07$ & $2.36 \pm 0.12$ & 2.0141 & 0.56 \\
2 & $3.32 \pm 0.04$ & $3.36 \pm 0.15$ & 2.0141 & 0.95 \\
Left otolith, anterior axis & & & \\
1 & $2.35 \pm 0.06$ & $2.26 \pm 0.16$ & 2.024 & 0.24 \\
2 & $2.85 \pm 0.09$ & $2.87 \pm 0.16$ & 2.024 & 0.80 \\
Right otolith, dorsal axis & & & \\
1 & $1.54 \pm 0.04$ & $1.55 \pm 0.10$ & 2.0010 & 0.79 \\
2 & $1.81 \pm 0.05$ & $1.84 \pm 0.09$ & 2.0010 & 0.60 \\
Left otolith, dorsal axis & & & \\
1 & $1.54 \pm 0.04$ & $1.49 \pm 0.07$ & 1.9971 & 0.24 \\
2 & $1.80 \pm 0.05$ & $1.79 \pm 0.07$ & 1.9971 & 0.68 \\
Right otolith, posterior axis & & & \\
1 & $2.28 \pm 0.08$ & $2.37 \pm 0.13$ & 2.0086 & 0.24 \\
2 & $2.74 \pm 0.10$ & $2.82 \pm 0.12$ & 2.0086 & 0.40 \\
Left otolith, posterior axis & & & \\
1 & $2.29 \pm 0.06$ & $2.23 \pm 0.16$ & 1.9996 & 0.36 \\
2 & $2.74 \pm 0.07$ & $2.69 \pm 0.16$ & 1.9996 & 0.54 \\
Scales & & & & \\
1 & $2.40 \pm 0.07$ & $2.36 \pm 0.12$ & 1.9897 & 0.56 \\
2 & $3.32 \pm 0.04$ & $3.36 \pm 0.15$ & 1.9897 & 0.64 \\
\hline
\end{tabular}

Note: Scale and otolith axes measured are indicated in Fig. 1 and sample sizes are provided in Table 2.

of known-age larval rainbow smelt (Osmerus mordax) were within $16.3 \%$ of the observed growth trajectories, but periods of zero or negative growth for larval fish are overestimated by the biological-intercept model (Secor and Dean 1992). The biological-intercept model can also reduce or remove the effect of Lee's phenomenon in annual BCLs (Campana 1990).

In other studies, validation with individually tagged fishes found Dahl-Lea or Fraser-Lee otolith back-calculation errors generally within $15 \%$ of observed lengths. For Atlantic cod (Gadus morhua) reared in pens with induced fast, slow, or variable growth, Smedstad and Holm (1996) found that all Fraser-Lee BCLs were within $10 \%$ of known lengths during a 2.5-year study. Holmgren (1996 found Dahl-Lea back-calculation errors of $15 \%$ or less for OTC-marked and individually tagged European eels (Anguilla anguilla) despite violation of the assumption of direct proportional growth between the otolith and body. For largemouth bass (Micropterus salmoides), Howells et al. (1995) found DahlLea BCLs errors of -6.8 to $9 \%$. Hales and Belk (1992) found differences of $1.5-10.6 \%$ between BCLs with the biological-intercept model and the actual lengths of bluegill aged 1-9; the greatest error $(>9 \%)$ was seen at the youngest ages (ages 1-3).

Verification of BCLs from the Dahl-Lea or Fraser-Lee model by other studies for other centrarchids indicates that these models can provide reasonable length estimates from otolith annuli. However, because individually marked fish or groups of fishes with known growth were not used, these studies do not constitute complete validation. Schramm et al. (1992) compared otolith BCLs using the Dahl-Lea and FraserLee methods for largemouth bass and found more accurate BCLs for the Dahl-Lea model compared with the FraserLee model. Heidinger and Clodfelter (1987) found no significant differences between empirical lengths, Dahl-Lea BCLs, and Fraser-Lee BCLs of age- 2 to age- 4 smallmouth bass. For white crappie (Pomoxis annularis), age-1 to age-3 length frequencies from spring samples corresponded well to FraserLee BCLs (Maceina and Betsil 1987). Schramm and Doerzbacher (1985) found a similar concordance of age-2 and age- 3 Fraser-Lee BCLs and length frequencies of black crappie (Pomoxis nigromaculatus); however, 52\% of the age-1 BCLs were below the minimum size captured in spring trawl samples. The discrepancy observed for age-1 black crappie by Schramm and Doerzbacher (1985) may be due to the size selectivity of their trawl.

For hybrid sunfish, segregation of right and left otoliths for back-calculation was unnecessary. No significant differences were observed for Fraser-Lee or biological-intercept model back-calculations from right and left otoliths. Boxrucker (1986) found similar results for Fraser-Lee otolith back-calculations for white crappie. Although not statistically tested, differences of Weisberg BCLs for right and left otoliths were all within $6.5 \mathrm{~mm}$ of each other for the OTCinjected hybrid sunfish.

For back-calculations from scales, both the Fraser-Lee and Weisberg methods produced estimates very close to the actual lengths. Although statistically significant, the differences of Fraser-Lee model BCLs from the actual lengths at the first OTC mark were $<4.3 \%$. Weisberg BCLs were closer to the actual lengths; all differences were $<2.2 \%$. However, the simpler Fraser-Lee model was found to be more precise than the Weisberg model, especially for younger ages, and was recommended for back-calculating growth of wild smallmouth bass and walleye (Klumb et al. 1999b). In this study, the observed error of both models likely lies within the range of body length measurement error (Gutreuter and Krzoska 1994).

The greatest error for BCLs from scales was seen at the first OTC mark; both linear models failed to accurately describe the early growth of these fishes. A similar result for the Fraser-Lee model was found by Klumb et al. (1999a) in another experiment with OTC-marked bluegill and hybrid sunfish. Since our fish were anesthetized during measurement and the mean radii of three scales was used for backcalculation, violation of the isometric assumption of scale and body growth is the most likely source of the greatest errors seen at the earliest OTC mark. The body-scale relationship for early fish growth is generally nonlinear (Regier 1962). An allometric body-scale relationship is only approximated with the linear Fraser-Lee, biological-intercept, and Weisberg models, necessitating caution when interpreting the earliest BCLs.

Validation studies (Davies and Sloane 1986; Howells et al. 1995; Klumb et al. 1999b) of older marked fishes in the wild indicate that Fraser-Lee BCLs from scales generally provided realistic estimates of historic fish growth. BCLs of individually tagged smallmouth bass and walleye underestimated the actual length at marking by $10 \%$ or less (Klumb et al. 1999b). Davies and Sloane (1986) found that Fraser-Lee 
Table 4. Width of OTC marks, percentage of the total scale radius within the mark, and mean number of circuli in the fluorescent band in the anteriolateral region of scales from 30 randomly selected hybrid sunfish injected with OTC.

\begin{tabular}{lrllll}
\hline $\begin{array}{l}\text { OTC } \\
\text { mark }\end{array}$ & $N^{*}$ & $\begin{array}{l}\text { Mean width } \\
\pm 2 \mathrm{SE}(\mathrm{mm})\end{array}$ & $\begin{array}{l}\text { Mean width as percentage } \\
\text { of total radius } \pm 2 \mathrm{SE}\end{array}$ & $\begin{array}{l}\text { Width range } \\
(\mathrm{mm})\end{array}$ & $\begin{array}{l}\text { Mean number of } \\
\text { circuli } \pm 2 \mathrm{SE}\end{array}$ \\
\hline 1 & 30 & $0.068 \pm 0.0098 a$ & $1.86 \pm 0.27$ & $0.030-0.147$ & $2.9 \pm 0.42$ \\
2 & 30 & $0.048 \pm 0.0056 b$ & $1.28 \pm 0.13$ & $0.020-0.098$ & $2.3 \pm 0.24$ \\
3 & 9 & $0.048 \pm 0.0064 b$ & $1.18 \pm 0.28$ & $0.029-0.078$ & $2.7 \pm 0.40$ \\
\hline
\end{tabular}

\footnotetext{
Note: Widths followed by different letters are significantly different (one-way ANOVA, Bonferroni multiple-range test: $P<0.0008)$.

*Sample size differs because not all fish survived to the third OTC treatment.
}

BCLs underestimated length at release for hatchery-reared rainbow trout (Oncorhychus mykiss) by $5 \%$ or less. For individually tagged largemouth bass (ages 3-8), Howells et al. (1995) found that Dahl-Lea BCLs underestimated known lengths in October by $2.4-21.4 \%$, with the greatest errors $(>8 \%)$ seen at ages 3 and 4 . These large errors seen by Howells et al. (1995) at the young ages are likely due to not using an intercept in the Fraser-Lee model in conjunction with possible late season growth before annulus formation. Additional verification for Fraser-Lee BCLs from scales of bluegill (Regier 1962) and pumpkinseed (Lepomis gibbosus) (Pierce et al. 1996) found that all length estimates were within $5 \%$ of measured lengths for other fish captured at the start or end of the growing season.

In our study with juvenile hybrid sunfish, we found that scale BCLs were more accurate than those from otoliths. Only one other validation study (Howells et al. 1995) compared Dahl-Lea BCLs from scales and otoliths. The range of errors that they found differed from our study in that error of otolith BCLs $(-6.8-9 \%)$ was narrower than that of scale BCLs ( -21.4 to $2.4 \%$ ), indicating greater precision of BCLs from otoliths versus scales of largemouth bass (ages 3-8). The errors for scales likely would have been smaller if Howells et al. (1995) had used the Fraser-Lee model with an intercept for scale BCLs. In a study that verified BCLs to empirical lengths of three species (ages 1-4) caught in April at the start of the growing season, otolith BCLs using the Dahl-Lea model and Fraser-Lee BCLs for scales were not significantly different from the observed lengths (Heidinger and Clodfelter 1987). However, for long-lived species, age assessments from scales generally can become unreliable, resulting in greater growth estimation errors (Howells et al. 1995).

\section{OTC mark width and scale measurement error}

The approximately 2.5 circuli occurring within the fluorescent band of the OTC mark in the scales from our hybrid sunfish concurred with other reported OTC mark widths. Kobayashi et al. (1964) reported that approximately two or three "ridges" were in the tetracycline mark in the anterior region of goldfish (Carassius auratus) scales. The red drum (Sciaenops ocellatus) scale pictured in Bumguardner (1991) showed two circuli in the bright OTC band.

Due to the width and "bleeding" of OTC marks, the specific location used to measure scale radii for backcalculations could potentially affect the accuracy of those length estimates. However, differences between BCLs for the Fraser-Lee and Weisberg models using scale radii mea- sured to the inside and outside edges of the OTC marks were negligible $(<3 \mathrm{~mm})$. Moreover, this small change in BCL also indicates that uncertainty of where a natural annulus starts with respect to the scale focus would not greatly affect length estimates for both models if scale radii are measured within $1 \%$ of the true annulus. However, the fish used in our study were less than age 2 ; misjudging an annulus by $1 \%$ on older fishes with crowded annuli near the scale's edge may result in greater back-calculation errors. Smedstad and Holm (1996) increased otolith radii by $3 \%$ to study uncertainty in location of the true otolith radius that corresponded to the time of length measurements; they found insignificant changes in Fraser-Lee BCLs. Care should always be taken to accurately measure bony structure radii, but minor errors do not appear to appreciably change length estimates.

In summary, this experiment, along with our other validation studies in the laboratory (Klumb et al. 1999a) and field (Klumb et al. 1999b), provides fisheries researchers and managers information about the range of potential errors that can be expected from back-calculating fish growth. All BCLs in this study for otoliths and scales using the FraserLee, biological-intercept, and Weisberg models were within $15 \%$ of the actual lengths. Whether the potential of $15 \%$ error in BCLs is tolerable depends on individual research or management objectives. Due to the greater accuracy of scales, we recommend using scales over otoliths for backcalculating growth of juvenile hybrid sunfish. The FraserLee and Weisberg models had similar, small ranges of backcalculation error for scales. However, model choice depends on a study's specific objectives, since growth rates for individual fish cannot be derived with the Weisberg model.

Although otoliths can provide more reliable age assessments for many older fishes (Heidinger and Clodfelter 1987; Howells et al. 1995), back-calculation error was much more variable than for scales in our study with juvenile hybrid sunfish. Further detailed study of otolith - body growth relationships, beyond mere otolith-length on body-length regressions, is needed to improve growth estimates from these structures. At present, we recommend the simpler FraserLee model (without an intercept) or biological-intercept model for otolith back-calculations over the more complex Weisberg model. However, the potential decoupling of the otolith-body relationship and its effect on BCLs needs further study, which necessitates caution when interpreting otolith back-calculations for juvenile fish. Species-specific validation of back-calculation model performance should be attempted where possible, as has been recommended for techniques used to assess fish ages (Beamish and McFarlane 
1983). With further validation of back-calculation models for additional fish species, life stages, and aging structures, greater confidence can be placed in data derived by this popular and powerful fisheries tool.

\section{Acknowledgements}

The late Dr. Richard V. Frie proposed the unique idea of back-calculation model validation using OTC. We thank the Biology Department, University of Wisconsin, Stevens Point, Wis., for additional funding during the course of this project. Dr. Fred C. Copes procured the fish and provided laboratory space for the experiments. The digital image analysis system was assembled by William H. LeGrande. Ronald Brooks and Jeffery Ross from Southern Illinois University, Carbondale, Ill., provided instruction in the methods of OTC detection. The senior author thanks the many University of Wisconsin, Stevens Point, graduate and undergraduate fisheries students who provided assistance with rearing fishes during the 1.5 years of experimentation; he also thanks the Central Wisconsin Chapter of Trout Unlimited and the Musky Clubs Alliance of Wisconsin for scholarship awards. We thank Daniel W. Coble, Fred C. Copes, William H. LeGrande, Sandra L. Parker, and Nathan G. Smith for reviewing earlier versions of this manuscript. Our manuscript was greatly improved after constructive review by Steven E. Campana.

\section{References}

Babaluk, J.A., and Craig, J.F. 1990. Tetracycline marking studies with pike, Esox lucius L. Aquacult. Fish. Manage. 21: 307-315.

Beamish, R.J., and McFarlane, G.A. 1983. The forgotten requirement for age validation in fisheries biology. Trans. Am. Fish. Soc. 112: 735-743.

Boxrucker, J. 1986. A comparison of the otolith and scale methods for aging white crappies in Oklahoma. N. Am. J. Fish. Manage. 6: $122-125$.

Bradford, M.J., and Geen, G.H. 1987. Size and growth of juvenile chinook salmon back-calculated from otolith growth increments. In Age and growth of fish. Edited by R.C. Summerfelt and G.H. Hall. Iowa State University Press, Ames, Iowa. pp. 453-461.

Bradford, M.J., and Geen, G.H. 1992. Growth estimates from otolith increment widths of juvenile chinook salmon (Oncorhynchus tshawytscha) reared in changing environments. J. Fish Biol. 41: 825-832.

Bumguardner, B.W. 1991. Marking subadult red drums with oxytetracycline. Trans. Am. Fish. Soc. 120: 537-540.

Campana, S.E. 1990. How reliable are growth back-calculations based on otoliths? Can. J. Fish. Aquat. Sci. 47: 2219-2227.

Campana, S.E., and Neilson, J.D. 1982. Daily growth increments in otoliths of starry flounder (Platichthys stellatus) and the influence of some environmental variables in their production. Can. J. Fish. Aquat. Sci. 39: 937-942.

Carlander, K.D. 1982. Standard intercepts for calculating length from scale measurements for some centrarchid and percid fishes. Trans. Am. Fish. Soc. 111: 332-336.

Casselman, J.M. 1983. Age and growth assessment of fish from their calcified structures - techniques and tools. In Proceedings of the International Workshop on Age Determination of Oceanic Pelagic Fishes: Tunas, Billfishes, and Sharks. Edited by E.D. Prince and L.M. Pulos. NOAA Tech. Rep. NMFS 8. pp. 1-17.

Casselman, J.M. 1990. Growth and relative size of calcified structures of fish. Trans. Am. Fish. Soc. 119: 673-688.
Dahl, K. 1907. The scales of the herring as a means of determining age, growth and migration. Rep. Norw. Fish. Mar. Invest. 2(6): $1-39$.

Davies, P.E., and Sloane, R.D. 1986. Validation of aging and length back-calculation in rainbow trout, Salmo gairdneri Rich., from Dee Lagoon, Tasmania. Aust. J. Mar. Freshwater Res. 37: 289-295.

DeVries, D.R., and Frie, R.V. 1996. Determination of age and growth. In Fisheries techniques. 2nd ed. Edited by B.R. Murphy and D.W. Willis. American Fisheries Society, Bethesda, Md. pp. 483-513.

Everhart, W.H. 1948. A critical study of the scale method in backcalculating lengths of the smallmouth bass, Micropterus dolomieu Lacepede. Ph.D. thesis, Cornell University, Ithaca, N.Y.

Francis, R.I.C.C. 1990. Back-calculation of fish length: a critical review. J. Fish Biol. 36: 883-902.

Fraser, C.M. 1916. Growth of the spring salmon. Trans. Pac. Fish. Soc. 1915: 29-39.

Gutreuter, S., and Krzoska, D.J. 1994. Quantifying precision of in situ length and weight measurements of fish. N. Am. J. Fish. Manage. 14: 318-322.

Hales, L.S., Jr., and Belk, M.C. 1992. Validation of otolith annuli of bluegills in a southeastern thermal reservoir. Trans. Am. Fish. Soc. 121: 823-830.

Heidinger, R.C., and Clodfelter, K. 1987. Validity of the growth of the otolith for determining age and growth of walleye, striped bass, and smallmouth bass in power plant cooling ponds. In Age and growth of fish. Edited by R.C. Summerfelt and G.E. Hall. Iowa State University Press, Ames, Iowa. pp. 241-251.

Holmgren, K. 1996. Otolith growth scaling of the eel, Anguilla anguilla (L.), and back-calculation errors revealed from alezarin labeled otoliths. Nordic J. Freshwater Res. 72: 71-79.

Howells, R.G., Betsill, R.K., and Prentice, J.A. 1995. Age estimation and length back-calculation for known-age largemouth bass. Proc. Annu. Conf. Southeast. Assoc. Fish Wildl. Agencies, 49: 167-177.

Klumb, R.A., Bozek, M.A., and Frie, R.V. 1999a. Validation of the Dahl-Lea and Fraser-Lee back-calculation models by using oxytetracycline-marked bluegills and bluegill $\times$ green sunfish hybrids. N. Am. J. Fish. Manage. 19: 504-514.

Klumb, R.A., Bozek, M.A., and Frie, R.V. 1999b. Proportionality of body to scale growth: validation of two back-calculation models with individually tagged and recaptured smallmouth bass and walleyes. Trans. Am. Fish. Soc. 128: 815-831.

Kobayashi, S., Yuki, R., Furui, T., and Kosugiyama, T. 1964. Calcification in fish and shell-fish. I. Tetracycline labelling patterns on scale, centrum, and otolith in young goldfish. Bull. Jpn. Soc. Sci. Fish. 30: 6-13.

Lea, E. 1910. On the methods used in the herring investigations. Publ. Circonstance Cons. Perm. Int. Explor. Mer, 53: 7-25.

Lee, R.M. 1920. A review of the methods of age and growth determination in fishes by means of scales. Fish. Invest. Ser. II Mar. Fish. G.B. Minist. Agric. Fish. Food, 4(2): 1-35. (With errata)

Maceina, M.J., and Betsill, R.K. 1987. Verification and use of whole otoliths to age white crappie. In Age and growth of fish. Edited by R.C. Summerfelt and G.E. Hall. Iowa State University Press, Ames, Iowa. pp. 267-278.

Newman, R.M., and Weisberg, S. 1987. Among- and within-fish variation of growth increments in brown trout. In Age and growth of fish. Edited by R.C. Summerfelt and G.E. Hall. Iowa State University Press, Ames, Iowa. pp. 159-166.

Pierce, C.L., Rasmussen, J.B., and Leggett, W.C. 1996. Backcalculation of fish length from scales: empirical comparison of proportional methods. Trans. Am. Fish. Soc. 125: 889-898. 
Potter, G.E. 1925. Scales of the bluegill, Lepomis pallidus (Mitchell). Trans. Am. Microsc. Soc. 44: 31-37.

Regier, H.A. 1962. Validation of the scale method for estimating age and growth of bluegills. Trans. Am. Fish. Soc. 91: 362-374.

Ricker, W.E. 1979. Growth rates and models. In Fish physiology, bioenergetics and growth. Vol. VIII. Edited by W.S. Hoar, D.J. Randall, and J.R. Brett. Academic Press, Inc., New York. pp. 677-743.

Rijnsdorp, A.D., van Leeuwen, P.I., and Visser, T.A.M. 1990. On the validity and precision of back-calculation of growth from otoliths of the plaice, Pleuronectes platessa L. Fish. Res. 9: 97-117.

Schramm, H.L., Jr., and Doerzbacher, J.F. 1985. Use of otoliths to age black crappie from Florida. Proc. Annu. Conf. Southeast. Assoc. Fish Wildl. Agencies, 36(1982): 95-105.

Schramm, H.L., Jr., Malvestuto, S.P., and Hubert, W.A. 1992. Evaluation of procedures for back-calculation of lengths of largemouth bass aged by otoliths. N. Am. J. Fish. Manage. 12: 604-608.

Secor, D.H., and Dean, J.M. 1992. Comparison of otolith-based back-calculation methods to determine individual growth histories of larval striped bass, Morone saxatilis. Can. J. Fish. Aquat. Sci. 49: 1439-1454.

Sirois, P., Lecomte, F., and Dodson, J.J. 1998. An otolith-based back-calculation method to account for time-varying growth rate in rainbow smelt (Osmerus mordax) larvae. Can. J. Fish. Aquat. Sci. 55: 2662-2671.
Smedstad, O.M., and Holm, J.C. 1996. Validation of back-calculation formulae for cod otoliths. J. Fish Biol. 49: 973-985.

Strasdine, G.A., and McBride, J.R. 1979. Serum antibiotic levels in adult sockeye salmon as a function of route of administration. $\mathrm{J}$. Fish Biol. 15: 135-140.

Taubert, B.D., and Coble, D.W. 1977. Daily rings in otoliths of three species of Lepomis and Tilapia mossambica. J. Fish. Res. Board Can. 34: 332-340.

Weber, D., and Ridgway, G.J. 1962. The deposition of tetracycline drugs in bones and scales of fish and its use for marking. Prog. Fish-Cult. 24: 150-155.

Weisberg, S. 1986. A linear model approach to back-calculation of fish length. J. Am. Stat. Assoc. 81: 922-927.

Weisberg, S. 1993. Using hard-part increment data to estimate age and environmental effects. Can. J. Fish. Aquat. Sci. 50: 1229-1237.

Weisberg, S., and Frie, R.V. 1987. Linear models for the growth of fish. In Age and growth of fish. Edited by R.C. Summerfelt and G.E. Hall. Iowa State University Press, Ames, Iowa. pp. 127-143.

Whitney, R.R., and Carlander, K.D. 1956. Interpretation of bodyscale regression for computing body length of fish. J. Wildl. Manage. 20: 21-27.

Wright, P.J., Metcalfe, N.B., and Thorpe, J.E. 1990. Otolith and somatic growth rates in Atlantic salmon parr, Salmo salar L.: evidence against coupling. J. Fish Biol. 36: 241-249. 